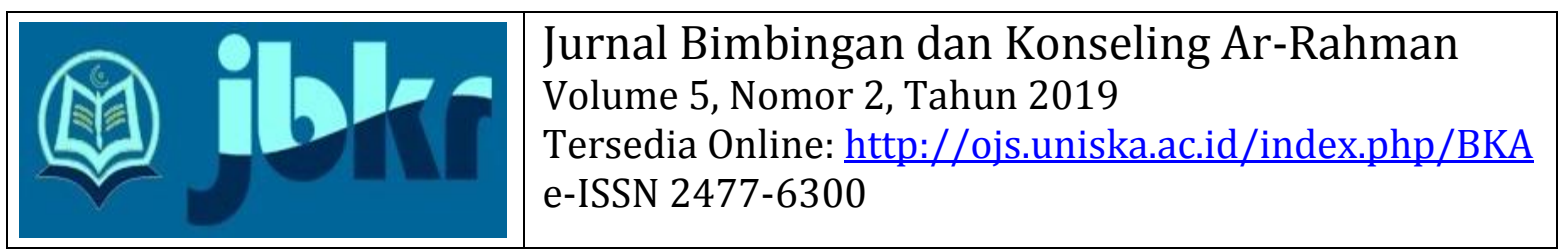

\title{
BIMBINGAN KELOMPOK TEKNIK SOSIODRAMA UNTUK MENINGKATKAN ETIKA PERGAULAN DI SEKOLAH PADA SISWA KELAS VIII DI SMP NEGERI 2 MARTAPURA
}

\author{
Rama, Sultani, Laelatul Anisah \\ Universitas Islam Kalimantan Muhammad Arsyad Al-Banjari \\ ramaabjb28@gmail.com
}

\begin{abstract}
ABSTRAK
Tujuan penelitian ini adalah untuk meningkatkan etika pergaulan siswa kelas VIII SMP Negeri 2 Martapura dengan teknik sosiodrama dalam layanan bimbingan kelompok. Latar belakang dari penelitian ini adalah adanya masalah pada siswa SMP Negeri 2 Martapura yaitu kurangnya kesadaran siswa beretika yang baik dalam pergaulan di lingkungan sekolah. Penelitian ini adalah penelitian eksperimen yaitu pre-eksperimental design onegroup pretest dan posttest. Prosedur penelitian ini adalah pretest-treatment-posttest. Sampel yang digunakan sebanyak 10 siswa dari 85 jumlah siswa kelas VIII D, VIII E dan VIII F di SMP Negeri 2 Martapura tahun ajaran 2019/2020 dengan teknik purposive sampling. Teknik pengumpulan data menggunakan skala pengukuran melalui angket. Validitas angket menggunakan Pearson Correlation dan reliabilitas angket menggunakan alpha cronbach. Analisis data pada penelitian ini menggunakan hitungan statistik deskriptif dan uji wilcoxon dengan aplikasi IBM SPSS Statistik 25.Kesimpulan hasil penelitian ini menunjukan bahwa adanya pengaruh bimbingan kelompok teknik sosiodrama terhadap meningkatkan etika pergaulan siswa kelas VIII SMP Negeri 2 Martapura atau dapat diterima.
\end{abstract}

Kata Kunci: Bimbingan Kelompok; Teknik Sosiodrama; Etika Pergaulan

\begin{abstract}
The purpose of this study was to improve the social ethics of eighth grade students of SMP Negeri 2 Martapura with sociodrama techniques in group guidance services. The background of this research is the existence of a problem in students of SMP Negeri 2 Martapura, namely the lack of awareness of good ethical students in relationships in the school environment. This research is an experimental study, namely pre-experimental design one-group pretest and posttest. The procedure of this study was a pretest-treatment-posttest. The sample used was 10 students from 85 students in class VIII D, VIII E and VIII F in SMP Negeri 2 Martapura in the 2019/2020 school year with a purposive sampling technique. Data collection techniques using a measurement scale through a questionnaire. The validity of the questionnaire using Pearson Correlation and the reliability of the questionnaire using alpha cronbach. Analysis of the data in this study used descriptive statistical calculations and Wilcoxon test with the application of IBM SPSS Statistics 25. The conclusions of the results of this study indicate that there is an influence of sociodrama technical group guidance on improving the social ethics of class VIII students of SMP Negeri 2 Martapura or acceptable.
\end{abstract}

Keywords: Sociodrama Technique; Group Guidance; Social Ethics

Dipublikasikan Oleh :

UPT Publikasi dan Pengelolaan Jurnal

Universitas Islam Kalimantan Muhammad Arsyad Al-Banjari Banjarmasin 


\section{PENDAHULUAN}

Etika pergaulan sangat dibutuhkan untuk kehidupan manusia agar memberikan batasan-batasan dalam berperilaku serta terciptanya suasana aman dan damai dalam berhubungan dengan orang lain yakni di keluarga, di sekolah dan di masyarakat. Oleh karena itu perlunya pemberian pemahaman kepada siswa tentang etika pergaulan agar mereka mampu menerapkan dalam kehidupan sehari-hari. Apabila siswa kurang memahami etika pergaulan, maka hal itu membuat mereka menjadi tidak terkontrol dalam pergaulan seperti berbicara serta tindakan terhadap teman sebaya, kakak kelas dan adik kelas serta yang lebih mengkhawatirkan yakni terhadap guru.

Etika pergaulan merupakan suatu perilaku atau sikap dalam berhubungan antara individu dengan individu lain yang sesuai dengan norma-norma dan nilai-nilai dalam kehidupan sehari-hari. Anggriani, Husen, Martunis (2016:69) mengartikan etika pergaulan adalah suatu hubungan tingkah laku individu yang di dalamnya terdapat suatu norma dan nilai-nilai yang digunakan dalam kehidupan seharihari, serta merupakan tolak ukur tingkah laku individu yang di gunakan masyarakat untuk menentukan baik buruknya suatu tindakan manusia dalam kehidupannya sehari-hari. Ciri-ciri etika pergaulan rendah adalah perilaku yang ditunjukkan selalu menyakiti orang lain, tutur kata yang diucapkan kurang menghargai dan menghormati orang lain, serta selalu menyinggung perasaan orang lain, mudah marah dan tidak bisa mengendalikan emosi, serta sikapnya tidak mencerminkan sopan santun dan ramah kepada orang lain.

Etika pergaulan yang baik perlu dimiliki oleh setiap siswa agar pada pergaulannya mampu berjalan dengan baik ketika berada disekolah, dirumah dan dilingkungan masyarakat. Jika permasalahan ini tidak terselesaikan, maka siswa tidak mampu untuk menampilkan diri yang sesuai dengan aturan atau norma yang berlaku sehingga dapat mengganggu, menyinggung, menyakiti perasaan dan pikiran orang lain serta tidak dapat menempatkan diri yang baik didalam suatu lingkungan seperti di sekolah, di rumah maupun di masyarakat.

Berdasarkan observasi awal di SMP Negeri 2 Martapura. Terdapat permasalahan yang sering terjadi di sekolah manapun pastinya ada siswa yang kurang dalam etika pergaulan. Pada observasi awal ditemukan siswa yang kurang menghargai teman lain. Seperti siswa yang mengejek temannya, siswa yang berbicara kasar terhadap temannya, siswa yang mengolok-olok nama orang tua temannya, ada juga siswa yang keluar masuk kelas saat guru mengajar saat jam pelajaran berlangsung. Berdasarkan informasi yang diperoleh dari guru bimbingan dan konseling juga diketahui bahwa permasalahan etika pergaulan di sekolah yaitu siswa yang hanya dari saling pandang memandang dengan siswa lain yang berujung dengan perkelahian, ada juga siswa yang saling adu mulut dengan siswa lain yang berujung dengan perkelahian.

Penelitian Murti (2018) menunjukkan bahwa bimbingan kelompok dapat meningkatkan pemahaman etika pergaulan siswa. Penelitian Anggriani, Husen, \& Martunis (2016) memberikan hasil yaitu dapat meningkatkan etika pergaulan siswa. Ditunjukan adanya peningkatan etika pergaulan siswa dari sebelum adanya bimbingan kelompok. Penelitian terdahulu di atas dapat ditarik kesimpulan bahwa permasalahan etika pergaulan mampu ditingkatkan melalu bimbingan kelompok. Berdasarkan observasi awal dan penelitian terdahulu menjadi alasan untuk mengangkat permasalahan etika pergaulan, sebab sangat menarik untuk diteliti dikarenakan etika pergaulan adalah permasalahan sosial yang perlu diselesaikan dimana pergaulan anak sekarang masih kurang dalam beretika dilingkungan sekolah.

Perlunya guru bimbingan dan konseling dalam penanganan etika pergaulan siswa. Dalam penanganan suatu permasalahan, guru bimbingan dan konseling mempunyai pelayanan konseling. Pelayanan konseling membantu dalam mengembangkan potensi, bakat dan minat yang dimiliki siswa secara individual, kelompok maupun klasikal. Pelayanan ini juga membantu mengatasi permasalahan yang dihadapi siswa di sekolah. "Jenis layanan konseling meliputi layanan orientasi, layanan informasi, layanan penempatan dan penyaluran, layanan penguasaan konten, layanan konseling perorangan, layanan bimbingan kelompok, layanan konseling kelompok, layanan konsultasi, layanan mediasi dan layanan advokasi" Prayitno (dalam Roshita, 2015:30).

Layanan yang dapat dilakukan guru bimbingan dan konseling agar membantu siswa memahami tentang etika pergaulan adalah bimbingan kelompok. Bimbingan kelompok adalah suatu pemberian bantuan kepada individu untuk menangani permasalahannya dalam kegiatan kelompok nelalui dinamika kelompok. Tohirin (dalam Lubis, Elita, Afriyati, 2017:46) mengemukakan pendapat bahwa layanan bimbingan kelompok merupakan suatu cara memberikan bantuan (bimbingan) kepada individu (siswa) melalui kegiatan kelompok. Dalam layanan bimbingan kelompok, aktivitas, dan dinamika kelompok harus diwujudkan untuk membahas berbagai hal yang berguna bagi pengembangan atau pemecahan bagi masalah individu (siswa) yang menjadi peserta layanan. Kelebihan bimbingan kelompok adalah lebih efisien dan efektif, terjadinya saling tukar pengalaman diantara anggota yang memberikan pengaruh dalam perubahan tingkah lakunya. 
Rama, Sultani, Laelatul Anisah

Jurnal Bimbingan dan Konseling Ar-Rahman

Volume 5, Nomor 2, Tahun 2019

e-ISSN 2477-6300

Layanan bimbingan kelompok terdapat suatu teknik yaitu teknik Sosiodrama. Teknik sosiodrama dipilih dikarenakan permasalahan ini berkaitan dengan masalah sosial yaitu kurangnya etika pergaulan pada siswa dilingkungan sekolah, jadi teknik sosiodrama dipandang tepat untuk meningkatkan etika pergaulan. Sanjaya dalam (Lubis, Elita, Afriyati, 2017: 46) mengatakan "bahwa sosiodrama adalah metode pembelajaran bermain peran untuk memecahkan masalah-masalah yang berkaitan dengan fenomena sosial, permasalahan yang menyangkut hubungan antara manusia seperti masalah kenakalan remaja, narkoba, gambaran keluarga yang otoriter, dan lain sebagainya”. Kelebihan dari teknik sosiodrama adalah sangat cocok untuk digunakan dalam menangani permasalahan sosial konseli serta membuat mental konseli di depan umum menjadi terlatih dan menjadi lebih kreatif dan berinisiatif.

\section{METODE}

Desain penelitian yang digunakan dalam penelitian ini yaitu, Pre-Experimental Design atau eksperimen. Pada metode ini tidak memiliki variabel kontrol karena masih terdapat variabel luar yang ikut berpengaruh terhadap terbentuknya variabel dependen dan sampel yang digunakan pada penelitian ini tidak dipilih secara random atau acak. Pada penelitian ini menggunakan bentuk One-Group Pretest-Posttest Design. Pada desain ini terdapat pretest, sebelum diberi perlakuan. Dengan demikian hasil perlakuan dapat diketahui lebih akurat, karena dapat membandingkan dengan keadaan sebelum diberi perlakuan (Sugiyono, 2016:111). Prosedur penelitian ini terbagi 3 tahapan, yaitu Pretest, Treatment dan Posttest.

Populasi siswa dalam penelitian ini adalah 85 siswa kelas VIII SMP Negeri 2 Martapura. Berdasarkan hasil skor angket skala etika pergaulan diambil sampel 10 orang siswa dengan teknik purposive sampling yaitu siswa yang memiliki skor terendah yang kemudian diberikan perlakuan layanan bimbingan kelompok dengan teknik sosiodrama. Teknik pengumpulan data menggunakan skala pengukuran melalui angket. Penelitian ini menggunakan Pengujian Validitas Konstrak dan dengan dilakukan pengujian Pearson Correlation dan uji reliabilitas menggunakan Alpha Cronbach yang kemudian dihitung dengan bantuan alat program SPSS versi 25. Kemudian akan dibandingkan keadaan sebelum serta sesudah diberi perlakuan dan akan di uji dengan uji wilcoxon.

\section{HASIL DAN PEMBAHASAN}

Berdasarkan hasil penelitian tingkat etika pergaulan siswa kelas VIII SMP Negeri 2 Martapura sebelum dengan sesudah mengikuti layanan konseling kelompok teknik sosiodrama. Hal ini dapat ditunjukkan dari hasil data pretest dan posttest bahwa hampir semua siswa mengalami peningkatan. Jadi skor siswa A pada awal dalam kategori tinggi skor 229 mengalami peningkatan menjadi 266 termasuk kategori tinggi, skor siswa MI pada awal dalam kategori tinggi skor 218 mengalami peningkatan menjadi 244 termasuk kategori tinggi, skor siswa G N $F$ pada awal dalam kategori tinggi skor 222 mengalami peningkatan menjadi 258 termasuk kategori tinggi, skor siswa M S pada awal dalam kategori tinggi skor 211 mengalami peningkatan menjadi 258 termasuk kategori tinggi, skor siswa M I N A pada awal dalam kategori tinggi skor 229 mengalami peningkatan menjadi 254 termasuk kategori tinggi, skor siswa M R pada awal dalam kategori tinggi skor 222 mengalami peningkatan menjadi 254 termasuk kategori tinggi, skor siswa M R pada awal dalam kategori tinggi skor 222 mengalami peningkatan menjadi 261 termasuk kategori tinggi, skor siswa $\mathrm{N} \mathrm{H}$ pada awal dalam kategori tinggi skor 225 mengalami peningkatan menjadi 260 termasuk kategori tinggi, skor siswa $\mathrm{S}$ W pada awal dalam kategori rendah skor 200 mengalami peningkatan menjadi 273 termasuk kategori sangat tinggi dan skor siswa W G pada awal dalam kategori tinggi skor 217 mengalami peningkatan menjadi 246 termasuk kategori tinggi.

Tabel 1. Hasil pretest dan posttest

\begin{tabular}{ccccc}
\hline $\begin{array}{c}\text { Nama } \\
\text { (Inisial) }\end{array}$ & Pretest & Kriteria & Posttest & Kriteria \\
\hline A & 229 & $\mathrm{~T}$ & 266 & $\mathrm{~T}$ \\
M I & 218 & $\mathrm{~T}$ & 244 & $\mathrm{~T}$ \\
G N F & 222 & $\mathrm{~T}$ & 258 & $\mathrm{~T}$ \\
M S & 211 & $\mathrm{~T}$ & 258 & $\mathrm{~T}$ \\
M I N & 229 & $\mathrm{~T}$ & 254 & $\mathrm{~T}$ \\
A & & $\mathrm{T}$ & 254 & $\mathrm{~T}$ \\
M R & 222 & $\mathrm{~T}$ & 261 & $\mathrm{~T}$ \\
M R & 222 & $\mathrm{~T}$ & 260 & $\mathrm{~T}$ \\
N H & 225 & $\mathrm{~T}$ & $\mathrm{ST}$ \\
S W & 200 & $\mathrm{R}$ & 273 & $\mathrm{~T}$ \\
W G & 217 & $\mathrm{~T}$ & 246 & \\
\hline Total & 2195 & & 2574 & \\
Mean & 219,5 & $\mathrm{~T}$ & 257,4 & $\mathrm{ST}$ \\
\hline
\end{tabular}

Untuk membuktikan hipotesis yang diajukan pada penelitian ini yaitu layanan bimbingan kelompok dengan teknik sosiodrama maka diadakan uji dengan uji wilcoxon pada Tabel 2 berikut : 
Rama, Sultani, Laelatul Anisah

Jurnal Bimbingan dan Konseling Ar-Rahman

Volume 5, Nomor 2, Tahun 2019

e-ISSN 2477-6300

Tabel 2. hasil uji wilcoxon

\begin{tabular}{lr}
\hline & Posttest - Pretest \\
\hline Z & $-2,803^{\mathrm{b}}$ \\
Asymp. Sig. & 0,005 \\
(2-tailed) & \\
\hline
\end{tabular}

Berdasarkan tabel di atas dapat dilihat bahwa data pretest dan posttest hasil analisis menggunakan wilcoxon pada aplikasi SPSS menunjukkan nilai Asymp.Sig sebesar 0,005 dengan demikian analisis tersebut diterima karena dasar pengambilan wilcoxon adalah <0,05 yang berarti (Ho) ditolak dan (Ha) diterima karena adanya pengaruh etika pergaulan pada siswa disekolah sebelum dan sesudah diberikan bimbingan kelompok teknik sosiodrama. Jadi bimbingan kelompok teknik sosiodrama berpengaruh terhadap meningkatkan etika pergaulan pada siswa kelas VIII SMP Negeri 2 Martapura.

\section{PENUTUP}

Berdasarkan pada hasil penelitian bimbingan kelompok teknik sosiodrama untuk meningkatkan etika pergaulan pada siswa kelas VIII di SMP Negeri 2 Martapura sebagai berikut :

(1) Etika Pergaulan yang dimiliki 10 siswa sebelum mendapatkan treatment dalam kategori tinggi dan rendah dengan skor terendah. Yang dapat terlihat hasil pretest, 1 siswa dikategorikan rendah dan 9 siswa dikategorikan tinggi; (2) Etika pergaulan yang dimiliki 10 siswa setelah mendapatkan treatment mengalami peningkatan skor dan masuk kategori tinggi dan sangat tinggi. Hasil posttest setelah mengikuti layanan bimbingan kelompok dengan teknik sosiodrama, 9 siswa dalam kategori tinggi dan 1 siswa dalam kategori sangat tinggi; (3) Setelah dilakukan pengujian dengan uji wilcoxon terbukti bahwa bimbingan kelompok teknik sosiodrama dapat meningkatkan etika pergaulan pada siswa kelas VIII di SMP Negeri 2 Martapura.

Dalam penelitian ini banyak keterbatasan yang terjadi, sehingga peneliti menyarankan beberapa hal yaitu : (1) Kepada guru bimbingan dan konseling agar melaksanakan bimbingan kelompok teknik sosiodrama dalam sesi pembelajaran untuk siswa yang rendah etika pergaulannya; (2) Siswa dapat menerapkan etika pergaulan yang baik dalam kehidupannya sehari-hari agar siswa mampu beretika baik dalam pergaulan dimanapun dia berada; (3) Peneliti selanjutnya agar menggunakan waktu sebaikbaiknya agar dalam penelitian mendapatkan hasil yang baik pula karena dalam penelitian ini waktunya sangat singkat.

\section{REFERENSI}

Anggriani, N., Husen, M., \& Martunis. (2016). Pelaksanaan Layanan Bimbingan Kelompok dalam Meningkatkan Etika Pergaulan Siswa SMK Negeri 1 Kluet Selatan. Jurnal Ilmiah Mahasiswa Bimbingan dan Konseling FKIP Unsyiah. 1(1), 65-71.

Lubis, A., Elita, Y., \& Afriyati, V. (2017). Bimbingan Kelompok Dengan Teknik Sosiodrama Meningkatkan Regulasi Emosi Pada Siswa Sma Di Kota Bengkulu. Jurnal Ilmiah Bimbingan dan Konseling. 1(1), 43-51.

Murti, F.K., \& Nursalim, M. (2018). Penerapan Bimbingan Kelompok Dengan Teknik Diskusi Kelompok Untuk Meningkatkan Pemahaman Etika Pergaulan Siswa. Jurnal BK UNESA. 8(1).

Roshita, I. (2015). Upaya Meningkatkan Perilaku Sopan Santun Melalui Layanan Bimbingan Kelompok Dengan Teknik Sosiodrama. Jurnal Penelitian Tindakan Bimbingan dan Konseling. 1(2), 29-35.

Sugiyono. (2016). Metode Penelitian Pendidikan: Pendekatan Kuantitatif, Kualitatif dan $R \& D$. Bandung: Alfabeta. 